\title{
Bananas para vender e histórias para contar: cultura alimentar local e identidades territoriais a partir de mercados orgânicos e agroecológicos
}

DOI

http://dx.doi.org/10.11606/ 1678-9857.ra.2020.178185
Annelise Caetano Fraga Fernandez

Universidade Federal Rural do Rio de Janeiro | Seropédica, R], Brasil annelisecff@yahoo.com.br | https://orcid.org/0000-0002-2659-9547
Silvia Regina Nunes Baptista

Universidade Federal do Rio de Janeiro | Rio de Janeiro, R], Brasil

s2baptista@gmail.com | https://orcid.org/0000-0001-7716-7229

Rafaela Paula da Silva

Universidade Federal do Paraná | Curitiba, PR, Brasil

rafaela.paula.da.silva.1991@gmail.com |

https://orcid.org/0000-0002-8363-4310

RESUMO

O presente artigo trata da disputa de sentidos a respeito da banana na cidade do Rio de Janeiro - especificamente no Maciço da Pedra Branca — área que no passado fazia parte da Zona Rural da cidade. Recentemente, a banana desta localidade ganhou o prêmio Maravil has Gastronômicas do Rio de Janeiro. Essa mesma banana, no entanto, é acusada por ambientalistas de ser uma planta exótica e seus produtores acusados de invasores de áreas de proteção ambiental. Sob outra perspectiva, a banana para seus produtores é um cultivo orientado ao mercado. Contudo, é também o mercado (orgânico/agroecológico) que ao conferir crescente notoriedade à banana específica, projeta também o bananeiro, a memória do lugar e a cultura alimentar local. Com base na análise de corpos discursivos - orais e escritos - a respeito da banana, buscamos construir um contexto (conjunto de textos) que revela as tensões sociais deste território.

Bananas to sell and stories to tell: local food culture and territorial identities of organic and agro-ecological markets

ABSTRACT This article addresses the dispute involving the different meanings of the banana in the city of Rio de Janeiro, especially in the Pedra Branca Massif — an area that in the past was part of the city's Rural Zone. More recently, the banana from this location received the Gastronomic Wonders of Rio de Janeiro Award, however, this same banana is accused by environmentalists of being an exotic plant and its producers accused of invading environmental protection areas. From another perspective, the banana for its producers is a market-oriented culture. However, it is also the market (organic/agroecological) that, by making the local banana known, also projects the banana producers, the memory of the place and the local food culture. Based on the analysis of discursive bodies — oral and written — about the banana tree, we try to build a context (set of texts) that reveals the social tensions of this territory.

KEYWORDS

Social meanings, Agri-food systems, Markets, Sertão Carioca, Rio de Janeiro 
Olha a banana

Olha o bananeiro

Eu trago bananas prá vender

Bananas de todas qualidades

Quem vai querer

Jorge Benjor

\section{INTRODUÇÃO}

A bananeira é uma planta presente na paisagem brasileira. Com diversas variedades e consumida de diferentes formas, a banana é tida como um alimento barato e cotidiano da vida nacional. É também fonte de subsistência para agricultores que a cultivam em encostas sombreadas e, ao se especializarem nesta cultura de mercado, são denominados bananeiros.

$\mathrm{Na}$ cidade do Rio de Janeiro, a produção de bananas preservou características rústicas de cultivo e ainda depende da utilização de animais de carga para "puxar a banana". Na concepção leiga, é um choque descobrir que esta fruta tão típica e estabelecida há séculos em nosso território é classificada como uma planta exótica e incompatível com a preservação das encostas, transformadas em áreas de proteção ambiental na cidade. Com alguma regularidade, são veiculadas na mídia denúncias sobre as "plantações ilegais" e seus responsáveis, os "agricultores invasores" dessas áreas ambientais. Plantas e pessoas que habitam a paisagem da antiga Zona Rural da cidade são assim ameaçadas de remoção por certa leitura conservacionista, que prega a incompatibilidade entre espaços de produção e espaços de conservação.

Já nos mercados orgânicos e agroecológicos ${ }^{1}$, a banana deste lugar tem ganhado crescente notoriedade. Parte desta projeção se deve à ação de mediadores institucionais e de organizações que têm promovido o reconhecimento dos modos de vida agrícolas na Zona Oeste da cidade. Ao trabalhar as disputas de sentido em torno da banana, o presente artigo tem como objetivo descrever a trajetória desta pequena agricultura frente à cidade e sua ressignificação a partir de um debate sobre relocalização da cultura alimentar trazido pelo movimento agroecológico e seus mercados.

Como metodologia, este trabalho fez uso de textos: produção bibliográfica, documentos, artigos de jornais, vídeos e alguns depoimentos, todos a respeito da banana, procurando descrever como essas fontes expressam diferentes conjunturas e mudança de sensibilidade em relação ao modo de vida agrícola do Maciço da Pedra Branca ${ }^{2}$. Por um lado, procuramos colocar em diálogo textos produzidos em momentos distintos, e, por outro, apresentamos alguns textos que, recentemente divulgados na mídia, apresentaram intensa circulação de ideias e resultaram na produção de novos textos. Nesse sentido, destacamos que o registro desses materiais discursivos, assim como o acompanhamento do processo de reconhecimento dos

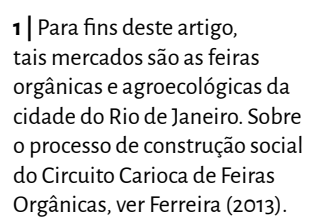

2 | Situado na Zona Oeste do Rio de Janeiro. Na face Leste, tem seus limites no bairro da Taquara, Colônia, Camorim, Vargem Grande e Vargem Pequena. Ao Sul, limita-se com as localidades do Crumari e Guaratiba. Na face Oeste, com o bairro de Campo Grande. $\mathrm{Na}$ face Norte, limita-se com os bairros de Senador Camará, Bangu, Realengo e Sulacap. 
sistemas agrícolas locais (Santilli, 2009) é resultado de pesquisa de longa duração das autoras (Fernandez, 2009, 2015, 2016a; Baptista, 2014; Silva, 2017) ou ainda de sua presença em campo durante a realização de eventos e atividades.

Usamos a noção de contexto tal qual é concebida por Dominick LaCapra (1983) e Sarmento (1998), que nos informa que o contexto de produção de um texto não é simplesmente a realidade empírica sobre a qual ele se apoia, mas é (in)formado pelo conjunto de textos que, em diálogo, constituem o universo argumentativo de uma época. Para LaCapra, portanto, a realidade é textualizada de várias formas e o pesquisador está necessariamente implicado nos processos de significação e interpretação da realidade. As autoras assim reconhecem sua implicação na construção deste campo argumentativo, seja pela seleção dos textos postos em conversa, seja pela circulação de seus próprios textos ao longo da última década.

\section{O SERTÃO CARIOCA: O PRIMEIRO TEXTO E O CONTEXTO DE REFLEXÕES SOBRE A BANANA, O BANANEIRO E A PAISAGEM}

O livro O Sertão Carioca foi publicado em 1933 pelo cronista, desenhista e naturalista autodidata Armando Magalhães Corrêa e retrata o modo de vida da antiga Zona Rural (hoje, Zona Oeste) da cidade do Rio de Janeiro. Nesta obra, são descritos, de modo sensível, os impasses vividos por agricultores desta localidade frente ao processo de urbanização e desenvolvimento de novas relações de produção que ameaçavam as possibilidades de reprodução das condições de vida dos "sertanejos". Mais do que apenas uma bela descrição da paisagem e dos "tipos humanos" matriz discursiva sobre a sertanidade ${ }^{5}$ inaugurada com a obra de Euclides da Cunha que produziu e vem produzindo diferentes versões sobre a diversidade social brasileira, sobre a dicotomia campo/cidade, litoral/sertão. A descrição do lugar, portanto, é utilizada para compreender as especificidades dos contingentes populacionais mais afastados dos núcleos civilizados do país, em contraste com as áreas mais urbanizadas da cidade. Assim, retrata o isolamento dessa região, a simplicidade e a interação profunda dos habitantes com a natureza, através do extrativismo e formas rústicas de artesanato e agricultura, ao mesmo tempo em que demonstra a relativa proximidade física e econômica da cidade, pois são os núcleos de comércio e povoamento que permitem a esses "sertanejos" o ganho de seu sustento, a venda de suas mercadorias.

Entre os diversos "tipos humanos" descritos pelo autor — o manobreiro da represa, o pescador, a esteireira, tamanqueiro, machadeiro, o carvoeiro, o ambulante urbano, suburbano e rural etc.-- Corrêa também descreve o ofício do bananeiro. Ao descrevê-los, o autor retrata algumas de suas dificuldades: a discriminação dos modos de vida rurais frente aos hábitos urbanos; o abandono do meio rural pelos órgãos públicos e a importância da banana como um cultivo orientado ao mercado, permitindo aos produtores adquirir produtos que não possuem em seus sítios:
3| Termo utilizado pelo autor e que carrega consigo referências semânticas da sertanidade conforme nota abaixo.

4 | Corrêa estabelece uma tipologia de habitantes do Sertão de acordo com suas relações ou funções desempenhadas no meio natural: pescador, timoneiro bananeiro, tamanqueiro, entre outros. De acordo com Sarmento (1998), o autor reproduz a matriz organológica que balizou as ciências sociais em seus primórdios.

$\mathbf{5}$ | O jornalista Euclides da Cunha ao publicar Os Sertões em 1902 inaugura um novo modelo de interpretação da diversidade social brasileira, ao denunciar os contrastes entre um Brasil Atlântico, urbano e cosmopolita e um Brasil Sertanejo, pobre e atrasado. A partir desta obra uma legião de intelectuais se debruçou sobre a temática do sertão e seus inúmeros significados. 
Colhidos os cachos nos pés, vão sendo arrumados nos caminhos, para depois serem transportados por burros aos depósitos de beira da estrada de rodagem e, daí conduzidos por autocaminhões ao centro de exportação, no centro urbano, ou por tropas, nos jacás das cangalhas dos burros. É verdadeiramente interessante verem-se os cargueiros ou tropeiros que saem de todas as tocas da zona rural, alta noite, para chegarem, ao alvorecer, ao mercado, mas atualmente, as autoridades não os deixam passar de um certo ponto, por acharem vergonhosa a tropa...

O que mais me impressionou em Paris, em pleno Boulevard Raspail, foi um homenzinho com uma trompa, som rouco, anunciando queijo de cabra, em companhia de umas trinta belíssimas cabras. Como é diferente a mentalidade dos povos civilizados.

(...) Como verdadeiros abnegados, lutando contra todos os elementos e, finalmente abandonados por nossos dirigentes; quando por ventura, cometem qualquer delito, aplicase-Ihes logo a lei, mas a lei feita para 'almofadinha da cidade', não há compreensão de seu meio, de sua mentalidade e de sua vida rural, o que demonstra a necessidade do estudo do habitat rural, como faz a União Geográfica Internacional.

Ao voltarem ao seu rancho trazem o que comer para o dia seguinte, em companhia de sua companheira e filhos (Corrêa, 1933:142).

A citação de Corrêa demonstra a integração econômica da atividade agrícola com o centro urbano, embora em muitos outros trechos do livro o autor enfatize a ideia de um mundo apartado do meio urbano, destacando o isolamento cultural e abandono institucional a que são relegados os sertanejos. Maria Isaura Pereira de Queiroz (1978) aponta que o contraste entre o rural e o urbano ${ }^{6}$ surge no fim do século XIX, principalmente nas grandes cidades, como São Paulo e Rio de Janeiro, impulsionado pela riqueza do café. Trata-se, nos termos da autora, de um aburguesamento ou um contraste mais cultural do que econômico ${ }^{7}$, já que neste momento a cidade depende ainda fortemente das atividades rurais para o seu sustento. Então, para a autora, éjustamente a proximidade dos centros urbanos que garante a vitalidade desta agricultura.

A partir do processo de industrialização nas primeiras décadas do século $X X$, ocorre de fato um rompimento com o meio rural e a agricultura local passa a ocupar um lugar periférico no contexto de abastecimento da cidade que exige, cada vez mais, uma escala de produção maior e tecnificada. A obra de Corrêa é, neste sentido, um prenúncio do desaparecimento de uma agricultura rústica frente ao processo de urbanização e à imposição crescente de novas racionalidades capitalistas, que alteram o lugar desta agricultura no plano de abastecimento da cidade, reforçando as leituras a respeito da decadência desta atividade. Podemos apontar uma série de transformações socioespaciais, juntamente com alterações de legislação urbanística, que contribuíram para a crescente invisibilização da agricultura do Sertão Carioca. Destacam-se: a renomeação da Zona Rural como Zona Oeste ${ }^{8}$ e o incentivo aos usos industriais e residenciais, o processo intenso de especulação imobiliária na região.
6| Segundo Pereira de Queiroz (1978), uma série de romances do século XIX retratam o distanciamento entre os hábitos citadinos e aqueles da roça, ainda que a proximidade entre esses dois mundos garanta a vitalidade desta agricultura. A autora destaca os romances de Manoel de Macedo, que retratam a vida citadina do Rio de Janeiro: A moreninha (1844), O moço Loiro (1845), Rosa (1849) e, em referência às distâncias sociais em São Paulo, cita as comédias de Martins Pena e o romance de Bernardo Guimarães: Rosaura, a enjeitada (1883).

$7 \mid$ A partir de inspiração weberiana, Pereira de Queiroz (1978) propõe pensar as relações entre o meio rural e urbano a partir de três tipos ideais de relações econômicas e político-administrativas.

8| A divisão da cidade em Zona Sul, Norte e Oeste corresponde à divisão geográfica da cidade e é amplamente utilizada pela população. Em termos administrativos, destaca-se a o Decreto 3.800/1970 que aboliu a nomenclatura Zona Rural e dividiu o Estado da Cuanabara nas seguintes zonas: Área Central, Zona Portuária; Zona Industrial, Zona Turística; Zonas Residenciais de 1 a 6; Zona Especial de 1 a 7. 
No plano das políticas ambientais, a ameaça de urbanização sobre as encostas e mananciais do Maciço da Pedra Branca foi acionada como justificativa para a criação do Parque Estadual da Pedra Branca9 (doravante PEPB), no ano de 1974. A partir desta data, o Estado, por meio do poder legal de nomear este território protegido, definiu novos usos e representações para as áreas com elevação acima da cota altimétrica de 100 metros.

A agricultura, desde então, tornou-se duplamente invisibilizada, seja pelo imaginário conservacionista que faz existir a representação (Bourdieu, 2006) de uma área florestada "intocada", seja pelas próprias dinâmicas do mercado que relegaram esta pequena agricultura a uma condição periférica/local e fortaleceram a representação de que não existe agricultura no município. Paradoxalmente, a criação do Parque foi responsável pela manutenção de uma parcela desta atividade agrícola. Em outras palavras, o Parque conservou parte do Sertão Carioca (Fernandez, 2016a). Devido às restrições ambientais, que legalmente não admitem a moradia ou qualquer uso direto dos recursos naturais em parques, muitos cultivos foram abandonados e a mata se recompôs. Aqueles que ficaram, no entanto, não expandiram seus cultivos e passaram a defender sua permanência, destacando seu pertencimento ao lugar, sua identidade como agricultor e seu papel na conservação da natureza. Deste modo, os bananais cumprem o papel de marcar na paisagem florestada a existência dos agricultores e de um sistema agrícola formado por caminhos, casas de pau a pique, cercas e animais de carga.

Embora não se possa falar de um conflito aberto e da remoção iminente dos moradores e produtores do PEPB, a dimensão visível e estigmatizante da desterritorialização subjetiva a que se refere Sathler $(2007)^{10}$ se faz presente em reportagens recorrentes que acusam os produtores de invasores e ameaçam sua retirada do interior da unidade de conservação. Assim, na reportagem do Jornal $G_{1}$ de 27 de maio de 2011", lê-se: "Imagens mostram plantação ilegal de bananas em parque ambiental no Rio". Nesta matéria, o entrevistado e responsável pela Coordenadoria de Combate aos Crimes ambientais, José Maurício Padrone, afirma:

\footnotetext{
Existe um projeto, o projeto vai terminar no final do ano e a secretaria vai indenizar essas pessoas que estão lá, e vai acabar com a banana, com essa plantação de banana, e plantar mudas de Mata Atlântica nativa daquela região (Portal G1, 2011).
}

O projeto citado é, na verdade, o plano de manejo do Parque, que nesta ocasião sequer estava pronto. Em sua fala, o plano parece ser um instrumento técnico-científico ${ }^{12}$ que finalmente fornecerá a justificativa legal para a remoção dessas "pessoas" e de suas plantações. A criminalização dos produtores, com base em princípios da Legislação ambiental e dos valores conservacionistas, oculta a história da ocupação do Maciço da Pedra Branca. Ao chamá-los de invasores, inverte a relação de anterioridade

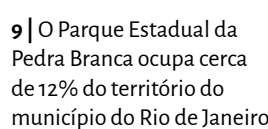

município do Rio de Janeiro.

10| Desterritorialização subjetiva define-se pelo sentimento de perda dos vínculos territoriais, por um estado permanente de ameaça de remoção, sem que de fato a desterritorialização física aconteça.

11 | Disponível em: http:// g1.globo.com/rio-de-janeiro/ noticia/2011/05/imagensmostram-plantacao-ilegalde-bana nas-em-parqueambiental-no-rio.html.

$\mathbf{1 2} \mid$ Muitas vezes, valores, concepções com apelo científico e não propriamente resultados de pesquisa embasada, são acionados para legitimar o processo decisório nas políticas ambientais. (Barreto Filho 2001: Carneiro; Medeiros; Laurent, 2008, Fernandez Oliveira; Dias, 2015). 
da presença dos produtores e seus cultivos na região. Implícita nesta fala, há também a condenação ao cultivo da banana, por ser esta classificada como planta exótica. E de fato, o Instituto Estadual de Florestas (IEF) ${ }^{13}$, órgão responsável pela administração do PEPB e outros parques estaduais, iniciou em 2007 um projeto de retirada de jaqueiras e bambuzais do Parque Estadual da Ilha Grande sob a alegação de que eram plantas exóticas invasoras. A ação causou grande choque e perplexidade entre a população da Ilha Grande e foi descrita por Prado e Catão (2010) como uma manifestação do etnocentrismo e assimetria nas relações com o outro, à medida que não considera o saber local e a importância de determinadas espécies nas práticas culturais das comunidades.

Tais polêmicas têm despertado o interesse pelo tema da agrobiodiversidade (Santilli, 2009), que procura destacar o papel do manejo humano, por meio da domesticação de plantas e animais, na biodiversidade e na diversidade genética in situ. Sob esta perspectiva, muitas florestas tidas como intocadas podem, na verdade, ter sido manejadas há milhares de anos (Balée, 2009, Adams, 1994, Oliveira; Silva, 2011, Fernandez; Oliveira; Dias, 2015).

A cultura da banana no Maciço da Pedra Branca causa controvérsia entre biólogos, ambientalistas, geógrafos, agrônomos e outros. Considerada uma planta exótica, alega-se que a bananeira não deixa crescer nada entre os seus pés, abre clareiras na mata, altera a vegetação original e aumenta o risco de deslizamentos em encostas. Outros, contudo, consideram que a bananeira apesar de ser uma planta exótica, já está estabelecida ali há muito tempo, sua cultura não tem se expandido e, do ponto de vista erosivo, seus efeitos são desprezíveis (Freitas, 2003). Este autor conclui então que tais resultados deveriam ser levados em consideração para o equacionamento de conflitos territoriais com as populações locais e que estas deveriam ser incorporadas aos projetos de conservação.

A colaboração interdisciplinar sobre agrobiodiversidade e paisagem têm contribuído para o estudo da historicidade da adaptação de plantas, homens e animais nas cadeias ecológicas. Os valores, práticas e conhecimentos locais que envolvem a utilização das espécies por grupos humanos são relevantes para problematizar o que merece ser protegido e conservado. $\mathrm{O}$ sistema agrícola ${ }^{14}$ (composto pela interação entre ambiente, técnicas, objetos, conhecimentos) passa a ser considerado pela sua potencialidade de conservação natural, mas também pelo seu valor cultural, pela engenhosidade de suas técnicas e riqueza cultural.

A longevidade deste cultivo no território brasileiro nos convida a pensar sobre a efetividade de se colocar a questão em termos da oposição exótico-nativo, em vez de se pensar as resultantes históricas da interação entre os elementos humanos e não-humanos na constituição secular ou mesmo milenar das paisagens. Conforme se lê na obra de Corrêa (1933:141): acredita-se que a banana tenha chegado no Brasil com os primeiros colonizadores. "Na Índia, Malásia e nas Filipinas, a banana é cultivada há mais de 4.000 anos. (...). Foi na América cultivada pela primeira vez em1516.”
13| Em janeiro de 2009, 0 Instituto Estadual de Floresta (IEF) junto com outros órgãos ambientais estaduais passaram a compor o Instituto do Ambiente (INEA).
14 | Em 2010, o Instituto do Patrimônio Histórico Artístico e Nacional (IPHAN) reconheceu - Sistema Agrícola Tradicional do Rio Negro (Amazonas) como patrimônio cultural brasileiro. A patrimonialização dos sistemas agrícolas resulta da compreensão de que determinados ecossistemas só podem ser preservados, se junto a eles, são assegurados os modos de vida de populações que os criaram e que os vem manejando. A recíproca também é verdadeira: não se pode assegurar a dinâmica de culturas e conhecimentos tradicionais associados sem a manutenção dos territórios onde tais modos de vida foram gestados. Ver em http://portal.iphan.gov. br/pagina/detalhes/75. 
A cultura rústica da banana no Maciço da Pedra Branca envolve um saber especializado e muito antigo de manejo e observação dos bananais, da relação com os burros que transportam as frutas pelos caminhos e as técnicas de amadurecimento correto das frutas. O agricultor Claudino em depoimento na reportagem "O Sertão Carioca”, publicada em um jornal de grande circulação, descreve o seu fazer cotidiano, evidenciando a penosidade do trabalho agrícola:

\footnotetext{
O segredo é roçar duas vezes por ano, e deixar a terra se alimentar da própria bananeira.

(...). Chega aqui eu tenho que cortar o cacho né, corto folha, forro as caixas tudo direitinho, arrumo, aí boto tudo no burro, carrego no burro, aí vou levar lá prá baixo prá associação. Quando o tempo tá assim de sol, a gente bota quatro caixas em cima do burro e desce que é uma beleza, mas quando dá esses temporais, de chuva mesmo; trovoada, então o burro desce, tem vezes que escorrega, rola pra grota abaixo, eu tenho que estar correndo, pegando, coitado, prá não machucar os bichos. Prá descer é brabo. A vida da gente é assim mesmo, tem que tocar prá frente, não pode desanimar não (Claudino da Costa apud Briso; Marenco, 2015).
}

\section{CULTIVOS PARA O MERCADO, O AUTOCONSUMO E A REINVENÇÃO DO SERTÃO CARIOCA}

A região do antigo Sertão Carioca teve diversas lavouras de mercado tais como o café, a laranja e a produção de carvão. Atualmente, a banana e o caqui são as principais lavouras de mercado. Esta última chegou no Maciço da Pedra Branca na década de 1960. A banana, de acordo com as fontes históricas, é o cultivo de mercado de maior longevidade no Maciço. Carcia Jr. (1983:16), ao tratar da distinção entre lavouras de mercado e de subsistência, afirma que os cultivos de mercado, ao produzirem valor de troca, permitem que os agricultores adquiram outros bens que não são produzidos em suas propriedades. Isso não significa que as lavouras de subsistência não são comercializadas, mas que a lógica que orienta o plantio e as formas como ele circula têm consequências sociais diferenciadas e cobrem diferentes esferas do consumo familiar.

Se por um lado, a relação com os mercados urbanos é uma condição histórica vivida pelas famílias agricultoras, por outro, o processo de urbanização e desenvolvimento das forças produtivas impõem necessidades crescentes de consumo que podem levá-las a um estado de desequilíbrio (Cândido, 1971), ou seja, o que se produz não é suficiente para adquirir outros produtos que se tornaram essenciais. Devemos destacar neste processo a democratização de acesso às geladeiras e a outros equipamentos domésticos, modificando hábitos alimentares e facilitando o armazenamento de carnes e, neste caso, diminuindo a pressão sobre alguns recursos naturais, entre eles a caça. Em contrapartida, observa-se a crescente dependência dos produtos externos à propriedade para abastecer as famílias.

As memórias dos agricultores do Maciço da Pedra Branca apontam para um passado de fartura, no qual poucas coisas precisavam ser compradas, contrastando 
com as inúmeras dificuldades atuais para plantar, seja pela falta de mão de obra, seja pela impossibilidade de expandir os cultivos, os caminhos malcuidados etc. Por fim, destaca-se também a questão geracional, uma vez que esses fatores, aliados às novas necessidades de consumo, levam a um crescente desinteresse dos mais jovens pela agricultura, que buscam outras atividades na cidade ameaçando a continuidade desta agricultura:

\begin{abstract}
Quando eu era criança, tinha muita gente nesta serra, a gente tinha maior alegria dia de domingo, de jogar bola, pelada, nos terreiros, ia no terreiro de um do outro, hoje você não vê mais isso, não vê mais nada. Tem pouca gente. Tem as pessoas que a gente conhece prá dentro do mato, mas hoje a maioria das pessoas tem suas casas lá embaixo. Quem já tá aqui tá, mas devagar vai morrendo, vai saindo fora e vai virando floresta que nem tá isso aí. Isso aí eu tenho tristeza mesmo. Acho que no futuro, isso vai ficar na história (Claudino da Costa apud Briso; Marenco, 2015).
\end{abstract}

Ainda que sempre se encontre a alternativa entre o cultivo de mercado e o autoconsumo, a tendência histórica desta agricultura do Maciço levou a uma crescente especialização na produção de banana. Dadas as restrições de um cultivo rústico transportado no lombo de animais e a concorrência da banana vinda de outros estados e produzida em grande escala, suas condições de mercado se tornam mais difíceis. Muitos desses produtores entregam sua produção a intermediários, recebendo muito pouco por ela.

O cultivo da banana requer pouco manejo se comparado a outros cultivos. Alguns agrônomos chegam a defini-la como uma agricultura extrativista, ainda que o uso combinado destes dois termos pareça contraditório. Sob uma perspectiva cultural e de adaptação das formas de trabalho locais, o interesse por outros cultivos (com exceção do caqui ${ }^{15}$ que também requer poucos cuidados) é pontual e apenas complementar à banana. Contudo, o crescimento do mercado de orgânicose a penetração dos valores da agroecologia trouxe novas possibilidades de reinvenção dessa agricultura. A participação dos agricultores do Maciço em feiras da Zona Sul da cidade contribuiu para divulgar seu espaço de vida em outros cantos da cidade (Prado; Mattos; Fernandez, 2012).

O pessoal lá de Ipanema, de Copacabana, no Leblon, na Tijuca, já compra nossos produtos. A gente foi criado aqui no mato, quando falava de Copacabana eu escutava era no rádio.

(...) A gente era orgânico e nem sabia. Nunca tinha ouvido essa palavra. (...) Há cinco anos, quando as feiras orgânicas começaram, tinha gente aqui em cima que me chamava de maluco. Atravessar a cidade para fazer feira, onde já se viu? Em Ipanema, a gente dava bom dia e as pessoas não respondiam. A gente era bronco mesmo, até deprimia. (Claudino da Costa apud Briso; Marenco, 2015).
15| A cultura do caqui, assim como a da banana, tem passado por um processo semelhante de valorização e vinculação territorial. A fruta faz parte da identidade visual de duas feiras agroecológicas da Zona Oeste. Desde 2011 se comemora o dia do Tira-Caqui, uma espécie de colheita comunitária, realizada sempre no dia 21 de abril; feriado de Tiradentes. Em 2014, o programa de televisão "Um pé de quê?", dedicado à história social das plantas, gravou um episódio sobre o caqui e visitou agricultores da região serrana do estado do Rio de Janeiro e do Maciço da Pedra Branca. A visita à Pedra Branca pode ser vista a partir do minuto 13:40 do vídeo "Um pé de quê?" https:// www.youtube.com/watch?v=0 v] $66 \mathrm{FHgBg \& t}=1127 \mathrm{~s}$, 
Segundo seus próprios relatos, os agricultores dizem que os consumidores querem saber como eles plantam, onde e como vivem. O interesse social por certos traços culturais no maciço da Pedra Branca tem estimulado os agricultores à produção de uma memória local, de valorização de sua história e de dignificação de sua atividade. Isso nos permite falar em um processo de patrimonialização ${ }^{16}$ (Gonçalves, 2009) do sistema agrícola do Sertão Carioca, que de acordo com o autor, é estimulado pelo sentimento da perda; de desaparecimento de determinados traços culturais que precisam ser salvaguardados.

A reportagem da qual foi extraída a citação acima teve grande repercussão social. Publicada na capa de uma edição de domingo do jornal O Clobo, a manchete anuncia: Uma viagem ao sertão da cidade: cariocas vivem de modo rústico sem luz elétrica nos morros mais altos do Rio e convida o leitor a tornar-se viajante de um "sertão amansado" (Vidal e Souza, 2010), como fez Magalhães Corrêa (1933), de um lugar que se encontra a poucos quilômetros dos bairros mais agitados do Rio de Janeiro. $A$ despeito do ar de flagrante exotização do Sertão Carioca, há indícios na reportagem de que o roteiro e os temas abordados foram construídos de forma participativa com seus entrevistados, os agricul tores. Os jornalistas, neste sentido, tiveram o mérito de compreender o sertão a partir da autorrepresentação dos "sertanejos".

\section{DA ROÇA INVISÍVEL AO PRÊMIO MARAVILHAS GASTRONÔMICAS}

Essas mudanças, portanto, têm início com o processo de conversão orgânica dos agricultores da localidade do Rio da Prata, no início dos anos 2000, mas ganha impulso coma abertura do Circuito Carioca de Feiras Orgânicas em 2010. No plano das agências ambientais, contudo, tem sido lento o reconhecimento do direito dos agricultores ao território. Em 2006, o Laboratório de Biodiversidade de Farmanguinhos/ Fiocruz, localizado no entorno do Maciço da Pedra Branca, desenvolveu um projeto de capacitação em plantas medicinais aos produtores locais, denominado Projeto Profito. A gestora do Parque foi receptiva ao projeto desde que fosse desenvolvido no entorno do parque, já que este não poderia ter uso direto e demonstrou otimismo em relação ao desaparecimento da agricultura e por conseguinte, dos agricultores que habitam o Parque:

\footnotetext{
O problema maioré o cara que está amarrado com a terra, mas um dado positivo é que os agricultores antigos estão morrendo. Penso mesmo que a tendência é o abandono da agricultura. Agora tem aqueles que têm prazer na atividade. A grande sorte nossa é que o jovem não tem mais interesse em agricultura.
}

Em 2007, mudou a administração do Parque e de toda a Secretaria do Ambiente, incluindo os novos gestores, mostrou-se favorável ao projeto como uma atividade ambientalmente compatível com a unidade de conservação, enquanto não
16 | Não estamos nos referindo a nenhum processo formal de reconhecimento, muito embora algumas dimensões deste universo socioespacial tenham sido reconhecidas institucionalmente. No Maciço da Pedra Branca, três comunidades quilombolas foram reconhecidas pela Fundação Palmares. Duas delas em 2014: o quilombo Cafundá Astrogilda e Camorim, e outra em 2017, o quilombo Dona Bilina. 
fosse equacionada a condição de permanência dos agricultores. Após a aprovação por ambas as instituições de um termo de cooperação técnica, o documento jamais chegou a ser assinado pelo órgão ambiental (IEF e posteriormente INEA), mas também jamais foi oficialmente negado. O silêncio, na verdade, revela o posicionamento desta gestão, aparentemente empenhada em demonstrar um caráter de mediação de conflitos, mas, na prática, negando direitos aos agricultores.

Para desapontamento dos gestores, o projeto rendeu numerosas conquistas políticas e possibilitou a inserção dos agricultores em redes de movimentos de agroecologia. A conversão orgânica de algumas associações e crescentes oportunidades de mercados orgânicos e agroecológicos promoveu novas reflexões sobre os mercados desejados, a identidade local dos produtos e vinculada a um modo de vida específico. A reportagem de O Globo de 13 de julho de 2013, intitulada "Roça Invisível: Produtores rurais do Rio tentam sobreviver à cobrança de IPTU e à falta de incentivos", apresenta com equilíbrio os diferentes pontos de vista sobre a manutenção da agricultura no Maciço da Pedra Branca. A reportagem dá voz aos agricultores, gestores ambientais e parceiros apoiadores da agricultura:

Meu avô era carvoeiro, meu pai plantava laranja, e desde menino eu trabalho na roça de banana, sem qualquer incentivo ou certificação oficial. Ajudamos a preservar o parque. Se a gente tiver que sair, vai para onde? Morar numa favela? - questiona Luís Carlos, enquanto caminha por sua roça de banana, que dispensa o uso de defensivos agrícolas ${ }^{17}$.

O secretário municipal de Meio Ambiente, Carlos Alberto Muniz, por outro lado, é taxativo: nada justifica produção agrícola em parques. Ele defende a erradicação das bananeiras das encostas da Pedra Branca, admite que o Plano Diretor dá margem à cobrança de IPTU em áreas com potencial agrícola, mas afirma que a isenção do imposto aos produtores continuará: - Essa produção na Pedra Branca não é positiva. É mais importante para a cidade desenvolver aquele ecossistema do que manter ali uma invasão.

O imbróglio levou para o lado dos produtores uma turma de renomados chefs. Teresa Corção, do restaurante Navegador, no Centro do Rio, coordena um movimento em defesa da produção orgânica da Pedra Branca. Ela lembra que, no momento em que a Europa discute a expansão de "cinturões verdes" em conglomerados urbanos, o Rio transita na contramão ao simplesmente negar o seu lado rural. - Se a pequena produção orgânica acabar no Rio, nossa comida do dia a dia vai vir industrializada, de longe. Perderemos completamente o controle de qualidade. Queremos construir uma relação com esses agricultores, que precisam de reconhecimento (Alencar, 2013).

Dada a grande repercussão da reportagem e com o objetivo de ampliar o acesso de mais agricultores ao debate, um dos membros do Projeto Profito ${ }^{18}$ gravou um vídeo ${ }^{19}$ apresentando a recepção da reportagem pelos agricultores. A ferramenta audiovisual permitiu registrar o direito de resposta deles, feito por Jorge Cardia e
17| O uso do termo defensivo agrícola ou agrotóxico costuma marcar posições ideológicas distintas no campo dos debates agrários e agrícolas. $O$ primeiro é utilizado por aqueles que defendem o agronegócio, seu pacote tecnológico e justificam a inevitabilidade do uso de determinadas substâncias no combate às pragas. Já os defensores da agricultura orgânica e agroecológica definem essas substâncias como agrotóxicos, enfatizando seu risco à saúde e à contaminação ambiental. Os agrotóxicos são definidos na lei federal $n^{\circ} 7.802$, de 11 de julho de 1989 , regulamentada pelo decreto $\mathrm{n}^{\circ} 4.074$, de 4 de janeiro de 2002 .

18 | O Projeto Profito embora tivesse como atividade fim a capacitação para o cultivo e manejo de plantas medicinais, pelos próprios entraves institucionais, legais e políticos encontrados para a execução do projeto, acabou por promover uma politização das questões que afetavam os agricultores e procurou criar canais de interlocução desse grupo com outros atores. As autoras Fernandez e Baptista participaram da construção e implantação do Projeto desenvolvido por Farmanguinhos/Fiocruz no período 2006-2016. Sobre o projeto ver o vídeo $A$ saúde está entre nós. 2013. https:// vimeo.com/70507705

19| "A roça é invisível para quem?” Disponível em https://www.youtube.com/ watch? $v=$ xcWiq48KLU. 
Cristina Santos, tornando-o um documento público que pudesse ter o mesmo alcance do texto jornalístico. Além disso, garantiu que o ponto de vista dos agricultores preservasse a força argumentativa característica do discurso oral.

\begin{abstract}
A roça é invisível? Pra mim não é invisível, porque sou de família tradicional daqui de Vargem Grande, da Pedra Branca, de mais de cento e cinquenta ou duzentos anos, entendeu? Então como invisível? (...) Tanto é que ela não é invisível que é dela que a gente tá trazendo nossa banana prá vender aqui na Vargem Grande e todo mundo já conhece os nossos produtos. Já sabe que nosso produto é orgânico, é bom, direto da roça. Então a roça não é invisível. Por que de onde sai esta banana? (...) Dela que sai o nosso sustento e nós estamos sustentando o povo de Vargem Grande com ela. E com mercadoria de qualidade. Vem pessoas de tudo que é lugar comprar, vem pessoas da Barra, do Recreio, Vargem Pequena, Camorim. Tudo pessoas que vêm comprar nossos produtos com a gente e querem mais produtos e a gente não tem (Baptista, 2013).
\end{abstract}

A leitura da reportagem demonstra que o uso do termo invisível pelo jornalista refere-se à falta de apoio, ao abandono institucional e ao desconhecimento da população sobre a atividade agrícola na cidade. Para o casal de agricultores, contudo, definir sua roça como invisível soou como uma ofensa. Fez-se necessário defender a sua história, o valor de sua atividade e de seus produtos nos mercados locais.

$\mathrm{O}$ vídeo foi gravado na Associação de Moradores de Vargem Grande. Na entrada do local funciona uma barraca de bananas. A criação deste ponto de venda partiu da ideia de mediadores do Profito, em conjunto com os agricultores da Associação Agrovargem, que organizaram a barraca em alguns eventos específicos. Posteriormente, a venda de bananas teve continuidade pela perseverança do agricultor Jorge Rodrigues que "fez o ponto". Funcionando em esquema de revezamento com outros produtores, o ponto de venda representou, para alguns deles, a possibilidade de abandonar a venda para intermediários e realizar a venda direta aos consumidores.

Enquanto nos mercados convencionais, e sob o olhar de grandes logísticas e cadeias longas de produção de alimento, a comida vem de nenhum lugar (Schmitt, 2011: 4), nos circuitos alternativos os alimentos passam a ser vistos a partir de seu vínculo com o produtor e com sua história de vida.

A alternatividade entre culturas de mercado e de autoconsumo (Garcia Jr., 1983), a venda direta ao consumidor, os mercados de proximidade e a valorização de alimentos locais, fazem parte de um conjunto de preceitos que o movimento agroecológico defende para o fortalecimento de uma "agricultura familiar camponesa" (Petersen, 2009) e que possa fazer frente às estruturas globais de produção de alimentos.

O surgimento de novas feiras alternativas ou pontos de venda nos bairros próximos aos seus sítios e a busca dos consumidores por "alimentos limpos"20 imputam a esses produtores o desafio de ofertar diversidade de produtos no tabuleiro,

20|Alimento limpó é um termo corrente para os alimentos produzidos sem agrotóxicos. 
limitada por décadas de especialização na produção da banana. Contudo, há que se pensar se o processo em curso de afirmação territorial permite aos agricultores acionar capitais simbólicos que podem alavancar diferentes oportunidades de renda (tais como o turismo de base comunitária, a fabricação de produtos processados) e não exclusivamente a diversificação da produção. De acordo com Favareto (2007), na construção de novas ruralidades, as atividades primárias cedem espaço a uma crescente heterogeneização das atividades econômicas, tais como os serviços ambientais e a produção de bens simbólicos.

É neste sentido que autores como Appadurai (2008) e Kopytoff (2008) vão além da discussão sobre formas e funções da troca, e buscam chamar atenção para os diferentes regimes de valor que são atribuídos aos objetos em situações de troca.

Junto ao seu caráter mercantil, a banana do Maciço da Pedra Branca passou a ser portadora de inúmeros atributos sociais, vinculados de modo mais amplo aos valores agroecológicos ${ }^{21}$ e de modo mais específico aos modos de viver do território. Inclusive a ela são atribuídos (pelos consumidores) valores de gosto e formas diferenciadas: são bananas mais saborosas, embora menores e com um aspecto mal cuidado, e quando comparadas àquelas vendidas no supermercados, são chamadas

21 | Entre eles, destacamos: ser livre de agrotóxicos, ser classificada como "comida de verdade" em oposição aos alimentos industrializados ou ultraprocessados. de "banana da roça" ou banana "arranhada".

Nos espaços das feiras se estabelece um processo pedagógico de aprendizado entre produtores e consumidores a respeito dos alimentos e seus preparos, gostos e regras de funcionamento dos mercados (uso de embalagens, preços, questões sanitárias, disposição das barracas e qualidade dos alimentos), assim como o partiIhamento de modos de vida, formas de conceber a divisão social da cidade etc.

Appadurai (2008), inspirado em Simmel, nos diz que a vida econômica é determinada pela troca de sacrifícios entre vendedores e compradores, contudo nem sempre a mensuração de sacrifícios é compartilhada entre ambos, especialmente em cadeias longas de comercialização ou de contextos interculturais. No caso em questão, vimos que pelas próprias características dos mercados agroecológicos e pela ação das mídias sociais, os consumidores alargam seu conhecimento sobre o sacrifício dos produtores em levar seus produtos à feira, além de outras adversidades enfrentadas no seu dia-a-dia. Os agricultores-feirantes, por sua vez, passam a considerar os sacrifícios dos consumidores, que envolvem cuidados com a saúde e a exigência de dietas restritivas, locais e horários limitados dos espaços de comercialização, questões de gosto e busca por alimentos específicos.

Para além dos mercados orgânicos, Fernandez (2016) descobriu, por acaso, a força de circuitos locais de escoamento da banana do Maciço da Pedra Branca. Em conversa com um vendedor ambulante de saladas de frutas no bairro da Praça Seca, soube que também nas feiras convencionais esta banana se destaca pelos seus atributos antioxidantes, o amadurecimento sem aditivos químicos e a ausência de cica: 
Hoje tive o prazer de conhecer o Cegê. Ele vende salada de frutas e sorvetes na Praça Seca, ao lado da Caixa Econômica. Em nossa conversa, ele conta que é economista e até se aventurou em uma pós-graduação no CPDA/UFRR], mas o trabalho não permitiu levar o projeto adiante. Seu carrinho é extremamente organizado, as frutas e sorvetes são armazenados separadamente e ele vai oferecendo as porções aos fregueses: "Manga? Melancia? Mamão? Banana?" Vejo a banana em rodelas bonitas e pergunto qual o segredo para ela não escurecer. Ele então responde que é a qualidade da banana. Ontem mesmo, diz ele, a banana não era boa, escureceu e deixou a minha salada feia. Gegê então completa: "a banana boa é a banana do morro, que compro daquele senhor que vende na feira da Praça Seca, ao lado do moço do coco. Esta banana vem do Recreio, não leva carbureto e mesmo verde não tem cica. A Banana que vem do Pau da Fome, Vargem Grande, Piabas ${ }^{22}$ é da melhor qualidade"(Fernandez, 2016b).

A projeção dos agricultores nos mercados orgânicos/agroecológicos e a aproximação com chefs de cozinha, movimentos de relocalização de alimentos ${ }^{23} \mathrm{e}$ segurança alimentar resultaram na premiação em dezembro de 2015 da banana de Vargem Grande, como Maravilha Gastronômica do Estado do Rio de Janeiro, na categoria "terra"(Soares, 2015). O prêmio teve o patrocínio do SENAC-RIO e do Governo do Estado. É este mesmo Governo que ainda criminaliza o cultivo de bananas no PEPB e que se recusa a oficializar qualquer acordo que confira segurança jurídica aos agricultores. Tratou-se, por isso, de um evento de grande simbolismo: os agricultores de Vargem Grande, os mesmos da roça invisível, serem recebidos e agraciados com a premiação no Palácio Guanabara, sede do Governo de estado.

Seguindo o caminho de celebrização da banana e do caqui, outros alimentos vão sendo aos poucos inseridos no mercado e apresentados como alimentos locais: a taioba, o inhame rosa, o cará moela, a serralha, algumas variedades de aipim e que não são encontrados nas grandes redes comerciais. Deste modo, junto ao incentivo de relocalização do sistema agroalimentar, um dos efeitos esperados é o resgate da culinária tradicional.

\section{A VALORIZAÇÃo PÚBLICA DA MEMÓRIA E DA CULTURA ALIMENTAR LOCAL}

Então, os primeiros ganhos foram de ordem política e simbólica. A memória local foi ressignificada, a identificação entre os agricultores e seus alimentos se tornou positiva (Velho, 2013: 63) e houve o reconhecimento de receitas tradicionais, algumas delas, tendo a banana como o principal ingrediente.

Pode-se observar também o aumento de pontos de venda direta em localidades mais próximas dos espaços agrícolas. Na Feira da Roça em Vargem Grande, por exemplo, produtores locais, vários dos quais autoidentificadoscomo quilombolas, semanalmente vendem bananas com outros alimentos de seus quintais, beneficiados $\mathbf{2 2}$ | Localidades no entorno do Maciço da Pedra Branca.

23| Encurtamento do caminho entre produção e consumo e valorização da cultura alimentar local (Schmitt, 2011). 
ou não. A valorização da cultura local fez com que, além da banana, eles passassem a trazer de forma contínua para as feiras doces tradicionalmente feitos para seu próprio consumo. Um fenômeno semelhante foi observado por Janine Gomes da Silva (2011) na agricultura familiar de Joinville (PR), onde os "pratos típicos" de famílias descendentes de imigrantes italianos passaram a ser reconhecidos como patrimônio cultural e valorizados e consumidos pelos turistas em comemorações anuais.

No primeiro semestre de 2016, vários potes de doce de banana decorados com o brasão da comunidade remanescente de quilombo Cafundá Astrogilda ${ }^{24}$ foram comercializados na Feira da Roça. Os doces eram feitos pela esposa de um dos representantes da comunidade. Embora, eles tenham deixado de ser vendidos algum tempo depois, ainda é possível comprar doces de banana na feira. Atualmente são vendidos doces de banana, abóbora e mamão com uma embalagem mais simples e sem brasão, por Jorgina Cardia, membro de um dos núcleos familiares da referida comunidade. Os doces são feitos por sua irmã, "da forma como se fazia antigamente"25 com rodelas de banana picadas. Ou seja, pela consistência e textura não servem para serem consumidos com pão e sim como uma sobremesa.

O doce ainda hoje é servido como sobremesa em comemorações tanto familiares quanto públicas feitas pelos quilombos do Maciço ${ }^{26}$. Além do doce, podemos citar também o ensopado de banana feito comumente no Bar tô na boa, por sua dona, Gisele Mesquita, também pertencente à Cafundá Astrogilda. Nas festas anuais do Dia da Consciência Negra, geralmente realizadas na frente de seu estabelecimento, serve-se feijoada. Porém, no dia 20 de novembro de 2016, em uma comemoração menor, porque havia falecido um dos representantes idosos da comunidade, Jorge Mesquita ${ }^{27}$, serviram para seus membros, parceiros e mediadores, o ensopado de banana.

Neste evento, a austeridade e o luto se evidenciaram por meio da comida. Assim, percebe-se a oposição entre os dois pratos e, por meio deles, a diferenciação entre a identidade quilombola pública exposta nas grandes comemorações — relacionada aos símbolos mais comuns de representação cultural afro-brasileira - e a própria especificidade da cultura local. O ensopado de banana, além de cumprir o papel de representar a tradicionalidade das práticas locais e das relações sociais à altura do homenageado, traz elementos de simplicidade e sobriedade condizentes com um momento de falecimento, enquanto a feijoada remete a momentos de festa e comemoração. Ao mesmo tempo, identifica-se no Quilombo Cafundá Astrogilda uma tendência comum a outras comunidades remanescentes de quilombo do Estado do Rio de Janeiro: em grandes festas comemoram conquistas políticas, datas importantes e arrecadam dinheiro com feijoadas públicas, como o Quilombo do Sacopã, São José da Serra e, bem mais próximo, o Quilombo do Camorim (também se localiza no Maciço) que já realizava feijoadas vários anos antes.

A feijoada, conforme escreveu Roberto da Matta, dentro do sistema culinário brasileiro, representa o alimento "cozido" situado entre o sólido e o líquido. Uma
24 | Cafundá Astrogilda é um dos núcleos familiares que compõem na acepção mais ampla o Quilombo Vargem. Seus membros são predominantemente agricultores de famílias que vivem no Maciço da Pedra Branca há aproximadamente 200 anos, porém como sua certificação é recente (16 de agosto de 2014), muitos trabalhos anteriormente já se referiram a eles apenas como agricultores.

25 | Definição dada pela própria vendedora sobre a receita do doce.

26 | Na $15^{\text {a }}$ Feijoada do Quilombo do Camorim (também localizado no Maciço) em 27 de novembro de 2016 , o doce de banana com pedaços foi servido em pequenos copos como sobremesa para os presentes.

27 Jorge dos Santos Mesquita que herdou de sua matriarca (Astrogilda Ferreira da Rosa) o respeito da comunidade, foi importante para o processo de certificação do Cafundá Astrogilda na Fundação Cultural Palmares. Além disso, nos anos seguintes foi uma das figuras públicas de referência, contando histórias na Ação Griô (visitas guiadas por membros da comunidade ao quilombo). 
herança da cultura ibérica, mas também alterada pela miscigenação. De modo que simbolizou, ao longo do tempo, essa identidade nacional híbrida. (2012:6) Câmara Cascudo (2011) afirma que, embora frequentemente seja associada à identidade negra, porque seria feita pelas escravas com os restos de comida da mesa dos senhores e isso esteja arraigado no imaginário nacional, suas raízes estariam fincadas nos cozidos ibéricos, feitos com a mesma lógica de cozinhar diversos alimentos juntos, e que no próprio continente africano, o feijão teria importância culinária bem menor se comparado ao milho e a mandioca.

A relação entre a feijoada e o ensopado foi explicada pela narrativa de Fátima Martins, uma das mulheres quilombolas que ajudou a preparar a feijoada na edição de 2015 desta festa. Em sua fala, estabelece uma relação de proximidade cultural maior com o ensopado de banana, porque a banana sempre existiu como uma base alimentar para os agricultores. Enquanto a feijoada era rara, uma iguaria para ocasiões específicas porque o custo das carnes era alto, apesar de sua importância simbólica.

\footnotetext{
A feijoada é a tradição, é a nossa tradição é feijoada e é feijoada, não é? Assim o ensopado de banana também é nossa tradição, ele lembra muito a minha infância. Ah, a banana humm minha mãe fazia muito, eu não sei fazer, não gravei, não gosto, dá muito trabalho. Mas comer eu adoro, sempre que sai sou a primeira a provar, mas a banana, o ensopado da banana minha mãe fazia muito, feijoada minha mãe fazia muito depois que deu a melhoria porque antes era mais difícil [...] Porque era mais difícil ter carne em casa, mas quando ela podia sempre comprava alguma coisa e fazia a feijoada e fazia pra gente, pouquinho, mas fazia, não com todas as partes...
}

O reconhecimento da banana pelos mercados orgânicos e/ou agroecológicos ocorreu anos antes da certificação de Cafundá Astrogilda, porém, de alguma maneira, a fruta se tornou uma referência em seu processo de reconhecimento, porque o cultivo histórico da banana e a culinária tradicional contribuíram para ancorar a identidade quilombola.

A banana e as formas de preparo não são apenas dos quilombolas, mas sim comuns aos agricultores que vivem há gerações no Maciço e as cultivaram e consumiram ao longo do tempo. Nesse sentido, a especificidade consiste em valorizar este alimento e tornar a cozinha local base para a identidade quilombola. Ou a premissa de que, para além das receitas pontuais, existe essa lógica mais ampla que conecta pessoas e alimentos em várias instâncias:

A cozinha de um grupo é muito mais do que um somatório de pratos considerados característicos ou emblemáticos. É um conjunto de elementos referenciados na tradição e articulados no sentido de constituí-la como algo particular, singular, reconhecível ante outras cozinhas (Maciel, 2005: 50). 
Nesse sentido, conforme propõe José Reginaldo Conçalves (2009:27-28), pode ser também um patrimônio cultural, porque abrange outras instâncias: econômica, moral, religiosa, mágica, política, jurídica, estética, psicológica e fisiológica. 0 patrimônio cultural está inserido em relações sociais, num determinado sistema referencial que produz sentidos, servindo ao mesmo tempo para formatar projetos e discursos. Assim sendo, não é possível por definição obter um único discurso linear de valoração. Mas os agentes em um espaço de disputa e negociação conseguem determinar o reconhecimento de certos valores em detrimento de outros, ainda que possam deixar de lado elementos importantes, que não se adequam bem ao contexto histórico-social.

A noção de patrimônio cultural, imaterial e/ou intangível, neste caso, confere valor formal à comida, como também a outras práticas culturais afro-brasileiras. Desta forma, podemos considerar que toda cultura possui materialidade e ao mesmo tempo toda materialidade é apropriada, significada e usada dentro da cultura. Portanto, quando nos referimos ao patrimônio cultural, imaterial ou intangível, indiretamente estamos tratando de aspectos materiais transitórios difíceis de tangenciar; as formas de fazer, que podem ser registradas, mas não congeladas e que são importantes testemunhos de nossa memória e identidade, preservados por grupos, regiões ou até pelo país. Por exemplo: formas de dançar, cozinhar, construir ou criar coisas que possuem uma certa continuidade temporal (Fonseca, 2004). Este valor permite consequentemente a "titulação coletiva de terras a comunidades negras tradicionais reconhecidas como 'remanescentes de quilombos' e o reconhecimento oficial de patrimônios imateriais relativos à herança de populações escravizadas" (Mattos; Abreu, 2013:107).

Isto se evidencia na proposta de pesquisa de Nina Bitar (2011) quando parte do pressuposto de que antes mesmo do Instituto de Patrimônio Histórico e Artístico Nacional (Iphan) reconhecer o acarajé como patrimônio cultural, as próprias baianas do acarajé já consideravam esta comida como uma referência importante de sua identidade religiosa e para o patrimônio da cultura afro-brasileira, o que foi posteriormente referendado pelo Estado com o processo de inventário do "Ofício das baianas de Acarajé". Logo, a comida deveria ser mantida com suas apropriações do espaço público, a relação de dádiva com suas divindades e a execução das obrigações religiosas correlatas no processo de preparação, oferta, exposição/venda e consumo do Acarajé.

Da mesma forma, embora Cafundá Astrogilda tenha singularizado para a sua própria constituição identitária as receitas da cozinha local feitas com a banana e consequentemente evidenciado sua especificidade e importância -, fez isso a partir de sua própria concepção de patrimônio no sentido mais essencial do termo, ou seja, aquilo tão importante que foi transmitido por gerações. Segundo Moraes (2005), trata-se de uma disputa de sentidos, que socialmente se configura por meio de novas interpretações discursivas em campo. Entre suas formas de comunicação estão o Facebook, conversas na feira, falas públicas em eventos acadêmicos e nas 
festas que realizam. Tornam-se protagonistas de sua trajetória e da defesa de um sistema agroalimentar integrado à cidade.

\section{CONCLUSÃo}

Ao longo do texto procuramos mostrar as disputas de sentido entorno do cultivo da banana no Maciço da Pedra Branca, a partir da confrontação de corpos discursivos — reportagens, depoimentos, documentos, livros e vídeos - que são portadores de possibilidades argumentativas de determinados contextos históricos. Observa-se que as novas orientações socioambientais e a inserção dos agricultores em movimentos de agroecologia e em circuitos orgânicos têm possibilitado aos agricultores algum protagonismo na produção de textos sobre sua própria história, produzindo assim novas formas de comunicação e polifonia. A crescente vinculação da banana ao território e a um modo específico de vida pelos mercados alternativos tem trazido visibilidade ao sistema agroalimentar local, assim como o resgate de traços da cultura alimentar, que podem contribuir para o fortalecimento desta agricultura ameaçada.

Annelise Caetano Fraga Fernandez é professora associada do Departamento de Ciências Sociais e do Programa de Pós-Graduação em Ciências Sociais da UFRR]. Possui mestrado em Antropologia e Sociologia e doutorado em Sociologia pela Universidade Federal do Rio de Janeiro. Coordena o Núcleo de Estudos em Ambiente, Território e Sistemas Agroalimentares (NEATS).

Silvia Regina Nunes Baptista é pesquisadora negra, do Núcleo de Estudos em Ambiente, Território e Sistemas Agroalimentares NEATS/UFRR], doutoranda pelo Programa de Pós-Graduação em Planejamento Urbano e Regional Universidade Federal do Rio de Janeiro, mestra em Ciências pelo PPCICS/ICICT/FIOCRUZ. Possui graduação em Pedagogia pela Faculdade Adventista de Educação e especialização em Cestão da Inovação em Fitomedicamentos (Farmanguinhos/FIOCRUZ).

Rafaela Paula da Silva é doutoranda em Educação (UFPR), mestra em História Social (PPGHS/UER] - 2017), e tem Especialização em Preservação e Cestão do Patrimônio Cultural das Ciências e da Saúde (COC/FIOCRUZ - 2016). É formada em licenciatura (UERJ - 2017) e bacharelado (UEPG - 2012) em História.

CONTRIBUIÇÃo DE AUTORIA: Não se aplica.

FINANCIAMENTO: Sem financiamento. 


\section{REFERÊNCIAS BIBLIOCRÁFICAS}

ADAMS, Cristina. 1994. "As Florestas Virgens

Manejadas". Boletim do Museu Paraense

Emilio Coeldi, Belém, v. 10, n. 1: 3-20.

ALENCAR, Emanuel. 2013. “A roça invisível: Produtores rurais do Rio tentam sobreviver à cobrança de IPTU e à falta de incentivos". Rio de Janeiro, O Clobo, 13 jul. Disponível em http://oglobo.globo. com/rio/produtores-rurais-do-rio-tentamsobreviver-falta-de-incentivos-9021943. Acesso em 23 de outubro de 2016.

APPADURAI, Arjun. 2008. A vida social das coisas: as mercadorias sob uma perspectiva cultural. Rio de Janeiro: Eduff.

BALÉE, William. 2009. "Culturas de Distúrbio e Diversidade em Substratos Amazônicos". In: Embrapa (org.). As Terras Pretas de Índio da Amazônia: sua Caracterização e uso deste conhecimento na criação de novas áreas. Manaus: Embrapa Amazônia, pp.48-52.

BAPTISTA, Silvia Regina Nunes. 2014. Comunicação oral em redes sociotécnicas orientadas a plantas medicinais: a relação entre informação científica e conhecimento tradicional. Rio de Janeiro, dissertação de mestrado, Instituto de Comunicação e Informação Científica e Tecnológica em Saúde.

BITAR, Nina Pinheiro 2011. Baianas do Acarajé: comida e patrimônio no Rio de Janeiro. Rio de Janeiro, Aeroplano.

BOURDIEU, Pierre. 2006. O Poder Simbólico. Rio de Janeiro, Editora Bertrand Brasil.

CÂNDIDO, Antonio. 1971. Parceiros do Rio Bonito. São Paulo, Duas Cidades.
BARRETO FILHO, Henyo. 2001. Da nação ao planeta através da natureza: uma abordagem antropológica das unidades de conservação de proteção integral da Amazônia brasileira. São Paulo, tese de doutorado, Universidade de São Paulo.

CASCUDO, Luís da Câmara. 2011. História da Alimentação no Brasil. São Paulo, Global.

CARNEIRO, Maria José; MEDEIROS, Camila; LAURENT, Catherine. 2008. "Uso das ciências na regulação ambiental: diálogos entre saberes e políticas públicas". In: $26^{a}$ Reunião Brasileira de Antropologia-CT 22, Porto Seguro, pp. 01-29. Disponível em http:// www.portal.abant.org.br/2013/07/06/anais26-rba/. Acesso em 29 de abril de 2018.

CORRÊA, Armando Magalhães. 1933. O Sertão Carioca. Rio de Janeiro, Imprensa Nacional.

FAVARETO, Arilson da Silva. 2007. "A longa evolução da relação rural-urbano para além de uma abordagem normativa do desenvolvimento rural". Ruris, v.1, n.1: 157-190.

FERNANDEZ, Annelise Caetano Fraga. 2016a. "O sertão virou parque: natureza, cultura e processos de patrimonialização". Estudos históricos, Rio de Janeiro, v. 29, n. 57, pp. 129-148. Disponível em http://www.scielo.br/scielo. php?script=sci_arttext\&pid=S010321862016000100129\&Ing=en\&nrm=iso. Acesso em 18 de setembro de 2017.

FERNANDEZ, Annelise Caetano Fraga. 2016b. "A salada de frutas do Gegê e a banana do morro". O Ser Tão Carioca, o7 jan. 2016. http://www.sertaocarioca.org.br 
FERNANDEZ, Annelise Caetano Fraga; OLIVEIRA, Rogério Ribeiro de; DIAS, Marcia Cristina de Oliveira. 2015. "Plantas exóticas, populações nativas: humanos e não humanos na paisagem de uma UC de Proteção Integral", Tessituras, Pelotas, v. 3, n. 1: 121-153.

FERNANDEZ, Annelise Caetano Fraga. 2009. Do Sertão Carioca ao Parque Estadual da Pedra Branca: a construção social de uma unidade de conservação à luz das políticas ambientais fluminenses e da evolução urbana do Rio de Janeiro, Rio de Janeiro, tese de doutorado, Universidade Federal do Rio de Janeiro.

FERREIRA, José. 2013. "Os agentes da construção política de mercados". Iluminuras, Porto Alegre, v. 14, n. 33: 87-99.

FREITAS, Marcelo Motta de. 2003. Funcionalidade Hidrológica dos cultivos de banana e territorialidades na paisagem do Parque Municipal de Crumari-Maciço da Pedra Branca-RJ. Rio de Janeiro, tese de doutorado, Universidade Federal do Rio de Janeiro.

FONSECA, Maria Cecília Londres. 2004. Patrimônio Cultural: por uma abordagem integrada (Considerações sobre materialidade e imaterialidade na prática da preservação). IPHAN, Rio de Janeiro. Disponível em http:// portal.iphan.gov.br/uploads/ckfinder/ arquivos/Anexo,\%2otexto\%202. pdf. Acesso em 19 de abril de 2018.

GARCIA JUNIOR, Afrânio. 1983. "Trabalho familiar: autonomia e subordinação". In: CARCIA JUNIOR, Afrânio. Terra de trabalho, trabalho familiar e pequenos produtores. Rio de Janeiro, Paz e Terra, pp.58-100.
KOPYTOFF, Igor. 2008. "A biografia cultural das coisas: a mercantilização como processo". In: A vida social das coisas: as mercadorias sob uma perspectiva cultural. Rio de Janeiro, Eduff, pp. 89-124.

LACAPRA, Dominick. 1983. Rethinking Intellectual History: texts, contexts, language. New York, Ithaca. MACIEL, Maria Eunice. 2005. "Identidade Cultural e Alimentação”. In: CANESQUI, Ana Maria; Carcia Rosa Wanda (org.). Antropologia e nutrição: um diálogo possível. Rio de Janeiro, Fiocruz, pp. 49-55.

MATTA Roberto da. 2012. "Sobre comidas e mulheres". CAFÉFIL: pensando bem a arte e a cultura. Juiz de Fora: UFJF, pp.16. Disponível em https://www.uff.br/ pensandobem/files/2012/02/texto-VII-2012. pdf. Acesso em 14 de maio de 2020.

MATTOS, Hebe e ABREU, Martha. 2013. "Lugares do tráfico, lugares de memória: novos quilombos, patrimônio cultural e direito a reparação". In: MATTOS, Hebe (Org.). Diáspora negra e lugares de memória: a história oculta das propriedades para o tráfico clandestino de escravos no Brasil imperial. Niterói, Editora da UFF, pp. 109-122.

MORAES, Nilson Alves de. 2005. “Memória social: solidariedade orgânica e disputas de sentido". In: CONDAR, Jô; DODEBEI, Vera (Orgs.). O que é memória social?. Rio de Janeiro, Livraria Contra Capa, pp. 89-104.

OLIVEIRA, Rogério Ribeiro, SILVA, Inês Machline. 2011. "História da paisagem e paisagens sem história: espécies exóticas e nativas manejadas na Mata Atlântica". In: PEIXOTO, Ariane Luna; SILVA, Inês Machiline (Org.). Saberes e usos de plantas: legados de atividades humanas no Rio de Janeiro. Rio de Janeiro: PUC-Rio, p. 69-92. v. 1. 
PEREIRA DE QUEIROZ, Maria Isaura.

1978. "Do rural e do urbano no Brasil."

In: PEREIRA DE QUEIROZ, Maria Isaura.

Cultura, sociedade rural, sociedade urbana

no Brasil. São Paulo, EDUSP, pp.46-67.

PETERSEN, Paulo. 2009. Agricultura

familiar camponesa na construção do

futuro. Rio de Janeiro, AS-PTA.

PRADO, Rosane Manhães. 2003. "As

espécies exóticas somos nós: reflexão

a propósito do ecoturismo na ilha

grande". Horizontes Antropológicos,

Porto Alegre, v. 9, n. 20: 205-224.

PRADO, Rosane Manhães; CATÃO, Helena.

2010. "Fronteiras do manejo: embates entre concepções num universo de unidade de conservação". Ambiente e Sociedade, Campinas, v. 13, n. 1: 83-93.SANTILLI, Juliana. 2009. Agrobiodiversidade e direitos dos agricultores. São Paulo, Peirópolis.

SARMENTO, Carlos Eduardo. 1998. "Pelas veredas da capital: Magalhães Corrêa e a invenção formal do sertão carioca". Rio de Janeiro. In: Anais ANPUH - VII Encontro Regional de História, Rio de Janeiro. Rio de Janeiro, CPDOC. Disponível em http:// cpdoc.fgv.br/producao_intelectual/arq/1094. pdf. Acesso em 12 de outubro de 2019.

SATHLER, Evandro Bastos. 2008.

"Populações residentes em unidades de conservação de proteção integral: a competência da lei (RJ) 2.393/95 para além do sistema nacional de unidades de conservação - SNUC". In: Anais $12^{\circ}$ Congresso Internacional de Direito Ambiental. São Paulo, Instituto o direito por um planeta verde, pp.705-722.

SCHMITT, Claudia Job. 2011. "Encurtando o caminho entre produção e o consumo de alimentos". Revista Agriculturas, v.8, n.3: 3-8.
SILVA, Janine Gomes da. 2011. "Pratos típicos" como patrimônio cultural: as narrativas orais (re)elaborando antigas receitas". Revista de História Oral, Rio de janeiro, v.14, n. 1: 49-62.

SILVA, Rafaela Paula da. 2017. A culinária como patrimônio cultural e elemento constitutivo da identidade quilombola no cafundá de Astrogilda. São Gonçalo, dissertação de mestrado, Universidade Estadual do Rio de Janeiro.

VELHO, Gilberto. 2013. Um antropólogo na cidade: ensaios de antropologia urbana. Rio de Janeiro, Jorge Zahar.

VIDAL E SOUZA, Candice; SOUZA. 2010. "O Sertão amansado". Sociedade e Cultura, v. 13, n. 1:101-110.

\section{MATERIAIS CONSULTADOS}

A roça é invisível para quem? 2013.

Direção: BAPTISTA, Silvia Regina Nunes.

6'39". Disponível em https://www. youtube.com/watch?V=_xcWiq48KLU. Acesso em 12 de agosto de 2019.

BRISO, Caio Barreto; MARENCO, Daniel. 2015. Uma viagem ao sertão da cidade: cariocas vivem de modo rústico sem luz elétrica nos morros mais altos do Rio. O Globo, Rio de Janeiro, o4 de outubro. Disponível em http://oglobo. globo.com/rio/o-sertao-carioca-17660130. Acesso em 05 de fevereiro de 2016.

Portal G1. 2011. "Imagens mostram plantações ilegais de banana em parque ambiental no Rio". 27 de maio. Disponível em http:// g1.globo.com/rio-de-janeiro/noticia/2011/05/ imagens-mostram-plantacao-ilegal-debananas-em-parque-ambiental-no-rio. html. Acesso em 14 de julho de 2016. 
ARTIGo | Annelise Caetano Fraga Fernandez, Silvia Regina Nunes Baptista e Rafaela

Paula da Silva | Bananas para vender e histórias para contar: cultura alimentar local

e identidades territoriais a partir de mercados orgânicos e agroecológicos

SOARES, Maraci. 2015. "Banana

agroecológica de Vargem Grande ganha o

prêmio Maravilhas Gastronômicas". Jornal

Abaixo Assinado de Jacarepaguá. dezembro.

Disponível em https://docplayer.com.

br/70662629-Banana-agroecologica-

plantada-em-vargem-grande-fatura-

o-premio-maravilhas-gastronomicas-

pagina-5.html Acesso em 23 maio de 2019.

Recebido em 1 de janeiro de 2020. Aceito em 7 de abril de 2020 . 